\title{
Designing Mini-Games as Micro-Learning Resources for Professional Development in Multi-Cultural Organisations
}

\author{
Sylvester Arnab ${ }^{1}$, Ludmila Walaszczyk ${ }^{2}$, Mark Lewis ${ }^{1}$, Sarah Kernaghan-Andrews ${ }^{1}$, Michael \\ Loizou $^{4}$, Alex Masters ${ }^{1}$, Jackie Calderwood ${ }^{3}$, and Samantha Clarke ${ }^{1}$ \\ ${ }^{1}$ Disruptive Media Learning Lab, Coventry University, UK \\ ${ }^{2}$ Sieć Badawcza ŁUKASIEWICZ - Instytut Technologii Eksploatacji, Poland \\ ${ }^{3}$ Falmouth University, UK \\ ${ }^{4}$ Centre for Post-Digital Cultures, Coventry University, UK \\ aa8110@coventry.ac.uk \\ ludmila.walaszczyk@itee.lukasiewicz.gov.pl \\ ac6055@coventry.ac.uk \\ ab6238@coventry.ac.uk
}

\begin{abstract}
The need for self-directed learning for professional development drives an increase in the delivery of easy to use 'just-in-time' resources that respond to the often-dynamic workplace and work culture. This is especially important in the era of globalisation, when the number of employees, who are culturally diverse, increases each year. Most medium and large companies operate in an international environment, and this is due to the expansion of international enterprises with branches in various countries that requires cooperation with foreign clients, and the employment of foreign nationals in their companies. In order to guarantee the effectiveness of workings in companies, there is a need for continuous education in the aspect of the cultural diversity. This paper explores micro-learning, which focuses on delivering brevity through bitesized learning units or short-term learning activities. Learning content in this case can take many forms, from text to interactive multimedia. These contents are often created on demand, which can sometimes be less contextualised and pedagogically informed. Based on a case study of the need for training on cultural risks in multi-cultural organisations, this paper focuses on the design of mini-games as playful learning resources for supporting an online learning platform that has been developed as a response to this training need. Fifteen mini-games have been developed to complement eight main topics related to cultural risks and to promote reflection, practice and the self-assessment of knowledge acquired through the platform. The main eight topics represent the risk areas identified that include cultural awareness, understanding different cultures, communication, learning styles, hierarchy, team-working, qualities in the working place, and stereotypes through a survey carried out with personnel $(n=154)$ from multi-cultural organisations across five countries - Cyprus, Italy, Latvia, Poland, and the UK. The discussions include unpacking the mapping of pedagogical and gameful design considerations based on Arnab et al.'s (2015) Learning Mechanics-Game Mechanics Mapping (LMGM) model. The paper also discusses the findings from the testing of the online platform across 5 countries including 166 participants (two-step testing). The insights provided will be valuable to researchers, practitioners, designers, and developers of micro-learning resources.
\end{abstract}

Keywords: game-based learning, mini-games, micro-learning, cultural risks, e-learning

\section{Introduction}

'Just-in-time' resources are often used to deliver brevity to employees' engagement with professional development that is deemed useful for productivity, awareness of specific regulations, and also wellbeing. Brevity through bite-sized learning (Hug, 2005) or training units is the main premise for micro-learning, which has gained traction in online training. Micro-learning has been used to support today's fast-paced world with abundant access to a myriad of resources and tools, making it challenging for learners to meaningfully absorb educational material and remain focused on a topic for hours on end (Shail, 2019).

Micro-learning contents are often created on demand and in a more passive form, where learners would simply consume content, such as short videos viewed in sequence or accessing content delivered in the form of simple infographics. Equipping learners with materials in different formats engages learners more effectively in their development towards strengthening their knowledge base (Shail, 2019). Interactive media such as mini-games (also called micro-games) have been increasingly delivered as micro-learning content. A more dynamic interaction with digital content such as mini-games could increase learners' self-efficacy (Alqurashi, 2017b).

Kapp and Defelice (2019) emphasise that like any other learning programmes, micro-learning should include careful design. Alqurashi (2017a) argues that considerations on contents, pedagogy, and technology influence the design of micro-learning environments. When games are used as instruments for facilitating this type of

(C)ACPIL

Reference this paper: Arnab, s., et al., 2021. Designing Mini-Games as Micro-Learning Resources for Professional Development in Multi-Cultural Organisations. The Electronic Journal of e-Learning, 19(2), pp. 44-58, available online at www.ejel.org 
learning, like any other game-based learning initiatives, designers need to consider the balance between learning and gameplay from pre-production through to post-production of interactive content (Arnab and Clarke, 2017), which includes activities such as identifying expected outcomes, choosing appropriate methods, and evaluating the developed resources.

Within the context of professional development required for addressing potential challenges associated with cultural risks in multi-cultural organisations, this paper discusses the design of digital mini-gaming activities as interactive micro-learning resources for complementing an online learning platform that has been developed as a response to this development need. Eight topics that represent the risk areas, including cultural awareness, understanding different cultures, communication, learning styles, hierarchy, qualities in the working place, and stereotypes have been derived through the use of a survey carried out with personnel $(n=154)$ of multi-cultural organisations across five countries - Cyprus, Italy, Latvia, Poland, and the UK as part of an Erasmus+ project. Fifteen mini-games have been developed to complement the eight topics to promote reflection, practice, and self-assessment of knowledge acquired through the online training platform. The paper discusses the design considerations and findings from the testing of the mini-games with $(n=166)$ participants.

The following section describes the background on cultural risks that covers the participating countries (Cyprus, Italy, Latvia, Poland, and the UK), followed by the discussions on microlearning and mini-gaming. The proceeding sections describe the methodology and analysis of the findings from the testing of the platform and the minigames.

\section{Cultural Risks in Multi-Cultural Organisations}

Cultural differences can prevent effective communication and collaboration between people and often, although unconsciously, cause misunderstandings or aggravate prejudices and stereotypes. Understanding the cultural value systems of different cultures is essential for anticipating the behaviour of individuals in a specific business environment. Research studies (e.g. Arasaratnam and Doerfel, 2005; Ochieng and Price, 2010; Walaszczyk, 2020) acknowledge the impact of culture on business operations across organisations, however there is insufficient information on how to measure and quantify cultural risks that can influence the productivity and wellbeing of employees at the various enterprise levels.

The annual report of the Chartered Institute of Personnel and Development (2018) acknowledges that prejudice and bias (whether unconscious or not) still exist in the workplace in the UK and are associated with discrimination (Jones et al., 2016; Triana et al., 2015). A similar situation is perceived in Cyprus (Singh, 2014; Hussain, 2018). Inequality is an ongoing challenge with issues ranging from lack of women in leadership positions to perceptions of disabled job applicants (McLaughlin et al., 2004; Lane \& Flowers, 2015). Access to jobs is also an identified aspect, where there is an issue of bias in recruitment, from job advert wording to call-back rates for interviews (Gaucher et al., 2011; Quillian et al., 2017). There is often a stigma influencing an individual's experience at work, with research highlighting the barriers faced by those with disabilities. Prejudices and stereotypes as cultural problems have also been identified in Poland (Daugeliene et al., 2016). Usually the rule is that if the Poles have never been abroad, they express more stereotypes than the Poles who travel. The stereotypes are related to negative expressions and feelings towards individual persons or the whole society, e.g. the Gypsies, the Romanians, or the Bulgarians. The identified nations are aware of stereotypes, therefore, there is often a problem with effective communication and understanding.

Communication in the cultural environments is also a challenge in countries like Italy, Poland, the UK, Cyprus, and Latvia. There are various communication styles, which can be found even within one culture, according to the individual's personality, social origin, education, and other factors, where the way in which the same language is used may differ (Rožukalne et al., 2017). The use of English idioms that do not always translate the same meaning to everyone and gender perceptions can affect the way people treat or expect to be treated by others. Providing information accurately and promptly is critical to effective work and team performance. People from different cultures vary on how they relate to content and style of communication. For example, people from some cultures may be reluctant to give supervisors bad news - while those from other cultures may exaggerate it. Some tend to resolve conflicts openly, accepting them as some kind of a challenge, whereby some will attempt to avoid potential breakouts of conflict as much as possible, seeing danger for the person's status and honour in the conflict situation (Hanovs, 2016). Another issue related to communication is language. For many immigrants, their mother tongue is still a second language e.g. in Italy, but they feel more comfortable 
communicating in their native language. This is especially true when it comes to safety rules, company policies, HR forms, and other essential and/or specific information (Heinz, 2014; Castignioli, 2017).

Another cultural problem identified in Italy is time, which can cause a misunderstanding such as the perception of overtime, or even the exact meaning of a deadline. Perceptions of time underline the importance of cultural diversity in the workplace, and how it can impact everyday work (Bussotti, 2017). The aspect of time is strongly related to schedules, which means that work can be impacted by cultural and religious events affecting the workplace.

All of the cultural risks mentioned above may be crucial in terms of effective working in the organisation. If any of these risks are identified, there is a need to prevent them - to minimise or even to try to eliminate them. One of the ways to do it is to educate the employees about the aspects of cultural diversity in order to make them more aware, especially when working in multicultural organisations.

\section{Micro-learning and mini-games}

There has recently been increased interest in the use of micro-learning as a learning strategy, even though the concept itself has been around for decades (Hierdeis, 2007). There are various definitions of micro-learning and what it means. Kapp and Defilice (2019) define micro-learning as "an instructional unit that provides a short engagement in an activity intentionally designed to elicit a specific outcome from the participant."

Short bursts of learning content and activities enabled by the micro-learning approach allow learners to access knowledge at their own pace and in a more modular manner, where longer sessions can cause mental fatigue (Shail, 2019). Individuals learn and perform better when they can engage with short and engaging content at their own pace, instead of attempting to take in vast amounts of complex information in one session (Mayer et al., 1999). Wang (2017) found that when used as part of a course, smaller chunks of content in the form of short videos viewed in sequence helped students to better retain information, improving their performance in endof-course tests.

Micro-learning can be part of a larger learning system, where resources may take many different forms and are not limited to one particular medium. Short engagement in this case refers to engagement in condensed learning activities that usually take between 1 to 10 minutes, designed for skill-based training, learning, and education (Shail, 2019). Online learning platforms that are currently exploiting micro-learning resources include Khan Academy $^{\mathrm{TM}}$, Udemy $^{\mathrm{TM}}$, and Coursera ${ }^{\mathrm{TM}}$.

Engagement with micro-learning content has been proven to impact learning outcomes positively (Wang, 2017; Girgiu, 2017). A more active interaction with such content can often increase learners' self-efficacy, where it can develop and boost learners' confidence in their capabilities to study the content in a digital environment (Alqurashi, 2017b). Activities in the form of interactive games for instance, allow learners to actively participate instead of passively consuming content as it is supplied. Tesco, a large supermarket chain, uses mini-games to train employees in compliance. Ten mini-games are delivered to ensure learners are not overloaded with content, with testing on a particular aspect integrated within each game. The various scenarios place the learners in different challenging situations, making the online learning engaging and interactive. 'Broken Coworker' is another example of micro-learning that engages learners through various interactive scenarios with a mix of comic and video styles. The interactive video aspect allows learners to make decisions as they traverse various scenarios. Rosmalen et al. (2014) implemented mini-games to teach research methods. They found that the challenge lies in creating a well-balanced design for both the short nature of a mini-game, and the level of complexity of deliverable content, in order to gain any learning effect.

Kapp and Defilice (2019) emphasise that micro-learning is not just a quick and easy way to improve upon a boring learning programme, as it can take just as long to design, develop, and implement. Alqurashi (2017a) argues that to create effective micro-learning environments, we need to pay close attention to design considerations related to content, pedagogy, and technology. When mini-games are used to support micro-learning, we face the same challenge in balancing learning and play. 


\section{Methodology}

This paper explores the use of mini-games as micro-learning resources based on an Erasmus+ project, which aims to develop training materials for addressing cultural risks associated with multi-cultural organisations. Aligning with the identified need to ensure that we balance both learning and gaming aspects in the design process, the methods include the synthesis of the subject matter that has informed the content of the online training platform, and the use of Learning Mechanics and Game Mechanics mapping (Arnab et al., 2015) for informing the design of the complementary mini-games as micro-learning resources.

\subsection{From topic identification to the development of open educational resources}

The development process included a three-step methodology. Firstly, an in-depth literature review was carried out to identify and understand the possible risks that can occur in multi-cultural organisations. Secondly, based on the synthesis of the risks identified through literatures, personnel from multi-cultural organisations, including managers and employees, were consulted towards identifying key competences that are necessary in order to work effectively in multi-cultural organisations. Altogether, there were 154 questionnaires collected in the five project partner countries: Cyprus, Italy, Latvia, Poland, and the UK.

The third phase involved designing and developing an open online educational platform with access to interactive educational resources, such as mini-games in various forms, which also include comic-book games and interactive video scenarios. The design process includes the mapping of learning mechanics against game mechanics (Arnab et al., 2015) to align the resources to the specific learning objectives that they were designed for. The mini-games are endogenous to the topics they are complementing, and can also be used as separate stand-alone resources for engaging learners.

\subsection{Testing of the interactive mini-game resources}

The aim of the testing was to gain feedback on the interactive resources that complement the online educational platform. A two-step testing process was applied (alpha testing and beta testing) - both referring to the testing of the full working solutions. Alpha testing aimed to gain feedback on all the training materials specifically for the paper is to provide an evaluation of the quality of the interactive mini-games resources. 71 participants were consulted, including students at the Private School of Economics in Radom, Poland, who registered for a module on 'Social aspects of the integration process in Europe'. The resources from the online training platform were used in formal teaching and learning as a response to the Covid-19 pandemic. The students completed an online questionnaire specifically targeting the mini-game elements after one month of online learning via the training platform.

The questions included:

- How engaging are the interactive media, such as mini-games?

- Do these mini-games support the specific learning objectives and topics?

- Do you think that they can be used separately as a learning resource?

- Which are the top three mini-games that are both engaging and educational?

During beta testing, feedback was collected to inform the final version of the online educational platform, for adapting it to the needs of the target groups. The beta testing was carried out between June and October 2020 involving 95 adult educators, trainers, and intercultural coaches working in multi-cultural organisations and also students learning about social aspects in different cultures. The participants evaluated the training contents, mapped against the respective learning outcomes. The online training modules, together with interactive media (mini-games), were also evaluated. The same questions were used for evaluating the mini-games resources.

In both testing phases, the participants assessed the interactive resources using a 1-5 linear numeric scale (1 very poor, 5 - very high).

\section{The Cultural Risks Online Educational Platform}

\subsection{Cultural risks as a subject matter - the identified topics}

The identified risks and challenges summarised in Section 2 were the starting point to design and develop the questionnaires for identifying key competences responding to the risks. The number of questionnaires collected in every country are as follows (see Table 1): 34 questionnaires in Cyprus, 33 in Italy, 30 in Latvia, 30 in Poland, 
and 27 in the UK. $31 \%$ of all interviewees were managerial staff in a multi-cultural organisation, $49 \%$ were employees working at a lower level in a multi-cultural organisation, and $20 \%$ were individuals interested in the topic of cultural risk. $79 \%$ of interviewees are working in a multi-cultural organisation at this moment, $13 \%$ have worked in such an organisation before, and $8 \%$ have never worked in a multi-cultural organisation. $54 \%$ of interviewees are working in private enterprises, $20 \%$ in NGOs, and $9 \%$ in universities or colleges. $6 \%$ were working in government organisations, $2 \%$ in municipality organisations, and $9 \%$ had another status. The survey ran between October 2018 - February 2019.

Table 1: Respondent demography

\begin{tabular}{|l|c|c|c|c|c|}
\hline \multicolumn{1}{|c|}{ Country } & Poland & Latvia & Italy & Cyprus & The UK \\
\hline Number of respondents & 30 & 30 & 33 & \multicolumn{5}{l|}{34} & 27 \\
\hline Type of respondents [\%] & 33.3 & 20.0 & 9.09 & 41.18 & 55.6 \\
\hline Managerial staff & 56.7 & 46.7 & 66.67 & 41.18 & 29.6 \\
\hline Employees at a lower level & 10.0 & 33.3 & 27.27 & 17.65 & 14.8 \\
\hline Other interested in the topic & \multicolumn{5}{|l|}{} \\
\hline Working place of the interviewees [\%] & 86.7 & 60.0 & 81.82 & 73.53 & 92.6 \\
\hline Multicultural organisation at present & 10.0 & 23.3 & 6.06 & 20.59 & 7.4 \\
\hline Multicultural organisation in the past & 3.3 & 16.7 & 12.12 & 5.88 & 0.0 \\
\hline Never in a multi-cultural organisation
\end{tabular}

Based on the results collected, both from the literature review and interviews with the target groups, it can be concluded that there is a great need for cultural education in these organisations. In the era of globalisation, the number of employees who are culturally diverse increases each year. Most medium and large companies operate in an international environment. This is due to the expansion of international enterprises with branches in various countries, that require cooperation with foreign clients and the employment of foreign nationals. Employers and employees face challenges associated with cultural differences, which may introduce risks that impact their respective organisations (Anglim et al., 2019; Ashkanasy et al., 2002; Masulis et al., 2012; Scarborough et al., 2019; Segal, 2019).

All the organisations participating in the research agree that cultural risks occur in multi-cultural organisations within their countries. Based on data gathered, it can be concluded that the vast majority of risks occurring are similar. Primarily, the risks may be caused by a different approach to culture-related working styles: individualism vs. collectivism or low-power distance vs. high-power distance. Communication risk is a large part of the problem, but communication is a very broad concept that includes linguistic (e.g. language barrier, misunderstandings resulting from the use of idioms) and non-linguistic issues (e.g. low/high-context culture). The indicated risks are associated with work culture and productivity as well as the social aspects such as risk of social exclusion in the work environment. Those issues related to the social aspects may cause the creation of subgroups, excluding people from other cultures. This exclusion may be due to underlying prejudices, discomfort, or unfamiliarity with other ethnic groups, or displeasure with changing policies and procedures. Comparatively, prejudices and lack of knowledge about other cultures may cause the self-isolation of culturally diverse employees. Exclusion is closely linked to work efficiency, because an excluded person (whether excluded by the group or through self-isolation) may lose the desire and commitment to work, feel uncomfortable, and experience a decrease in efficiency. From the analysis, managerial staff of the organisation should be culturally aware and place emphasis on stronger inclusion of people at risk of social exclusion at work.

Synthesis of the findings led to the identification of eight main topics that are considered, which include (1) an introduction to cross-cultural awareness, (2) understanding different cultures, (3) working with stereotypes, (4) communication skills, (5) teamwork and social integration, (6) leadership and hierarchy, (7) learning styles, and (8) qualities in the workplace.

Apart from the identification of the main topics, which represent the subsequent eight training modules, the hierarchisation of the modules has also been completed (by employees of the partners' organisations). The hierarchisation was performed using the Analytic Hierarchy Process (AHP) method (Saaty, 1996). The summary of the hierarchisation research is included in Table 2 (detailed results are presented in Appendix 1). 
Table 2: The Research Results Based on the Use of the AHP Method

\begin{tabular}{|l|l|l|l|l|l|l|l|l|}
\hline Module & M1 & M2 & M3 & M4 & M5 & M6 & M7 & M8 \\
\hline Mean & 0.244 & 0.211 & 0.092 & 0.120 & 0.138 & 0.045 & 0.083 & 0.066 \\
\hline Ranking & 1 & 2 & 5 & 4 & 3 & 8 & 6 & 7 \\
\hline
\end{tabular}

Source: Walaszczyk, 2020.

M1 and M2, corresponding to 'Cross-cultural awareness' and 'Understanding different cultures', were identified as most important. The least preferred modules were M6 and M8; corresponding to 'Leadership and Hierarchy' and 'Qualities in the Working Place'. This may stem from the fact that 'Cross-cultural awareness' and 'Understanding different cultures' modules include many elements, which are significant for better understanding cultural diversity. They include an unspecified range of elements belonging to the aspect of multiculturality.

The other modules are exclusively dedicated to one specified problem, e.g. team-working, stereotypes, learning styles.

\subsection{The Online Educational Platform}

The content of each topic ( 8 topics in 8 separate modules) was developed by the project partners in consultation with subject experts with the aim to enable resources within each topic to be used as a collective or as individual stand-alone resources. The presentation of both content and activities is highly modular (see Figure 1). Educators and learners can pick and choose resources that are relevant to their teaching and learning. Specific resources, such as visually attractive Microsoft Power Point slides, videos, and mini-games can also be delivered to learners as required to allow access to small bites of learning contents and activities.
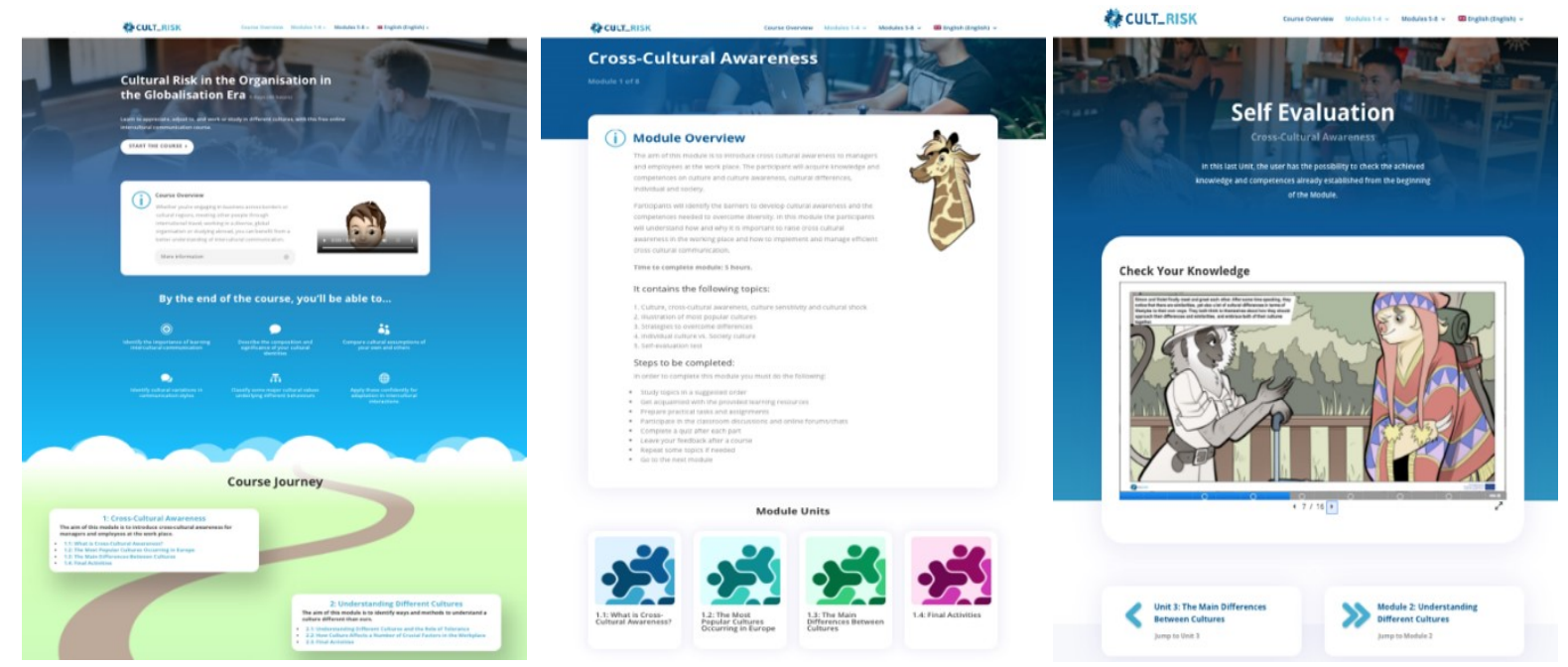

Figure 1: The online platform (https://culturalrisk-course.com/) with modular resources including mini-games

\subsection{Interactive mini-games}

Design of the micro-learning contents is influenced by pedagogy and technology. The browser-based educational platform requires micro-learning resources, including the mini-games, to be compatible with any web-browser. Mini-game development thus adopted existing authoring tools, such as Beaconing ${ }^{1}$ and $\mathrm{H}^{2} \mathrm{P}^{2}$, to enable quick development of interactive mini-game activities aligned with specific requirements of the different modules.

Four core aesthetic representations, based on the Mechanics-Dynamic-Aesthetics (MDA) Model (Hunnicke et al., 2004), were selected to create the game experience. They were (1) Challenge - Game as an obstacle course, (2) Discovery - Game as uncharted territory, (3) Fantasy - Game as make believe, and (4) Expression - Game as self-discovery. These experiences were drawn into the selection of the five main mini-game types for delivering micro-learning contents in an engaging way: (1) 'MCQ' quizzes provide a challenge in the form of multiple-choice

${ }^{1}$ http://beaconing.eu/results

${ }^{2}$ https://h5p.org/ 
questions with time pressure; (2) 'Drag-and-drop' quizzes fall under the challenge experience, where time pressure and the drag-and-drop action act as the obstacle course; (3) The animated target-and-swipe games also fall under the challenge experience, where players need to swipe the planets with the correct answers under a time constraint, (4) 'comic book' games provide a sense of fantasy with engaging scenarios played out by imaginary characters; and (5) 'video scenario' games provide scenarios played out by actors, where the player's response to questions posed in the narrative determines the ensuing narrative as players traverse the game, demonstrating experiences related to fantasy and expression.

Figure 2 shows examples of the different types of mini-game activities developed. There are 15 mini-games in total, comprised of two 'drag-and-drop' actions for filling in blank quizzes, one 'drag-and-drop' for word clustering quizzes, two 'MCQ quizzes', two 'animated target-and-swipe', six 'comic-based scenarios', and two 'video-based scenarios'.
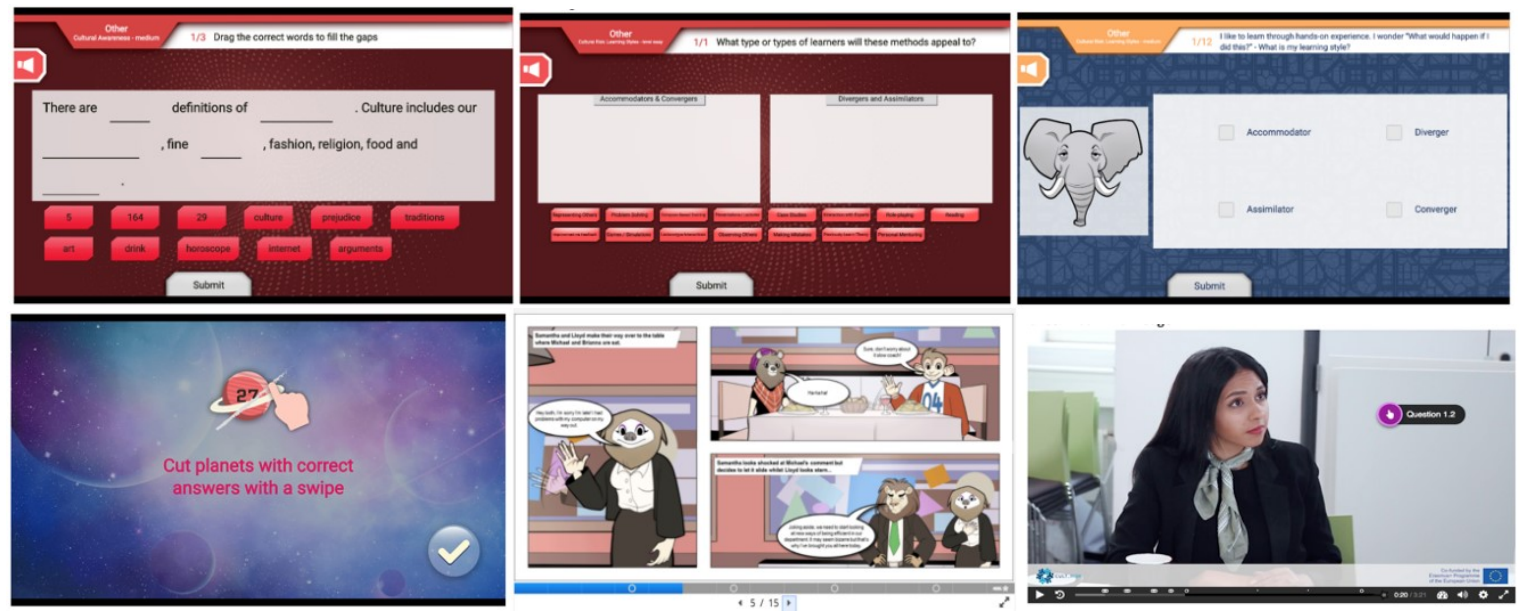

Figure 2: Mini-game types (left to right, top down): drag-and-drop (fill in the blank), drag-and-drop (word cluster), MCQ quiz, animated target-and-swipe, comic book, and video scenario

Examples of a summary of learning mechanics vs. game mechanics (LM-GM) mapping of 3 of the 15 mini-games are described below.

Planet Ninja (see Figure 3) is an Animated Target-and-swipe game featured within Unit 2 of Module 1 that aims to allow learners to quickly self-evaluate and assess what they have learnt from this unit's content within the online course. The topics explored in this game cover Cultural Sensitivity in an organisation, where the game takes learners through 4 rounds that require them to identify the correct keywords that relate to statements displayed to them before each round begins. It counts the number of correct and incorrect answers and provides learners with an overall feedback on their scores. The simple LM-GM mapping is summarised in Table 3.

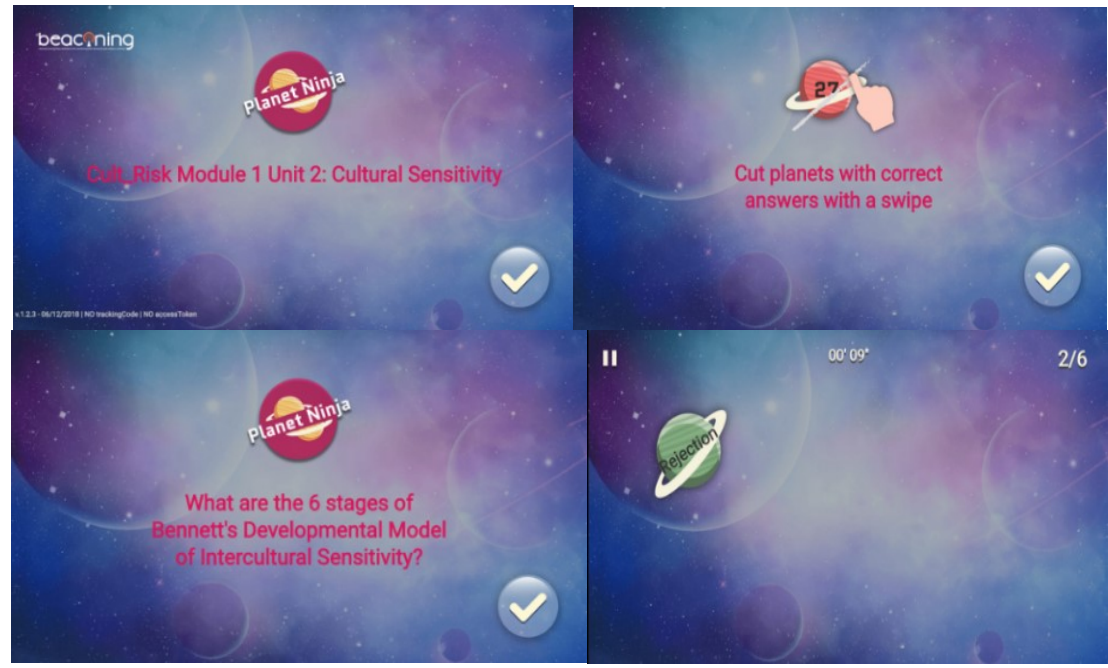

Figure 3: Snapshots of the Planet Ninja game authored using Beaconing 
Table 3: Simple LM-GM mapping of Planet Ninja

\begin{tabular}{|l|l|l|l|}
\hline Learning objective & Learning Mechanics & Game Mechanics & Implementation \\
\hline \multirow{2}{*}{$\begin{array}{l}\text { To identify } \\
\text { components and } \\
\text { attributes associated } \\
\text { to statements on } \\
\text { cultural sensitivity. }\end{array}$} & Identify & Selecting & $\begin{array}{l}\text { Through swiping action - cutting the planets } \\
\text { with the correct answer }\end{array}$ \\
\cline { 2 - 4 } & Repetition & Repetition & $\begin{array}{l}\text { The same mechanics are repeated in four } \\
\text { rounds. }\end{array}$ \\
\cline { 2 - 4 } & Assessment & Scores/Penalties & $\begin{array}{l}\text { Correct and incorrect answers will produce } \\
\text { visual feedback (explosion for wrong answers } \\
\text { and colourful confetti for correct answers) }\end{array}$ \\
\cline { 2 - 4 } & $\begin{array}{l}\text { Competition } \\
\text { Challenge }\end{array}$ & Time pressure feedback & $\begin{array}{l}\text { Statistics on correct and incorrect answers } \\
\text { are provided as feedback at the end. }\end{array}$ \\
\hline
\end{tabular}

The second example is the Check Your Knowledge game (see Figure 4) in Unit 3 of Module 3. This takes the form of a Comic Book quiz that assesses the learner's knowledge on cultural stereotypes and generalisations. Here, the comic-based narrative explores examples of scenarios that can occur within an office. Examples of stereotypical comments made towards an employee at an organisation highlight the impact that prejudices and cultural biases can have on everyone - not just the individual. Learners are asked to read through the comic book and answer questions that cover the topics of cultural stereotype factors and related risks, influences of cultural stereotypes in multi-cultural organisations and possible cultural biases, and different types of cultural stereotypes. The simple LM-GM mapping is summarised in Table 4.

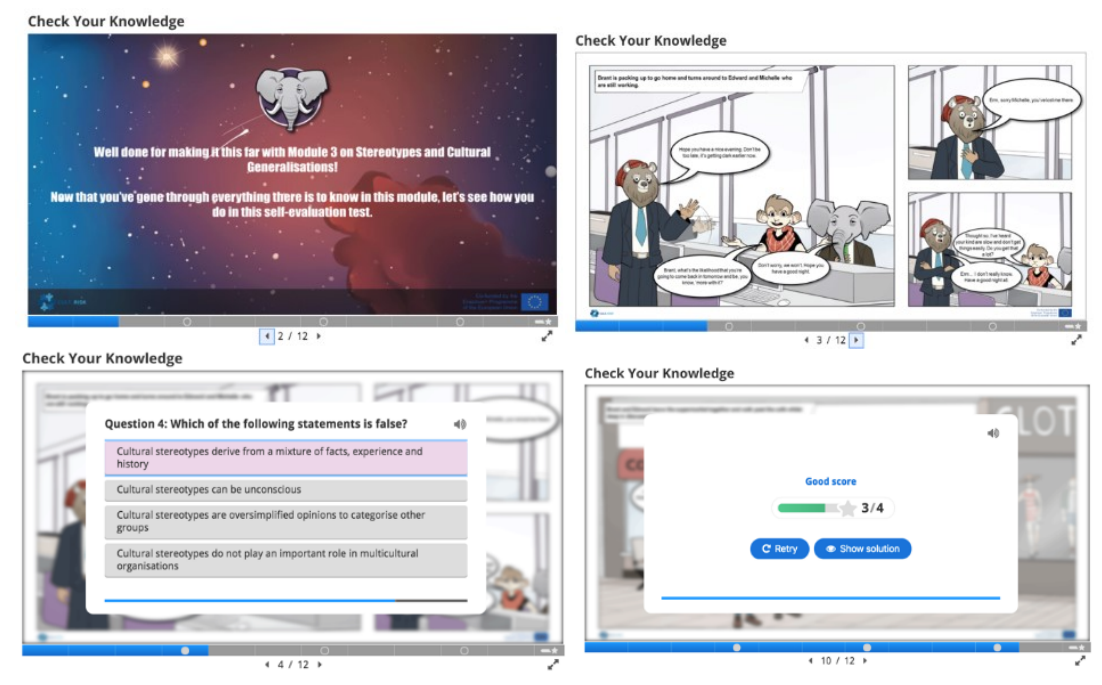

Figure 4: Snapshots of the Comic Book quiz game authored using H5P

Table 4: Simple LM-GM mapping of a Comic Book quiz game

\begin{tabular}{|l|l|l|l|}
\hline Learning Objective & Learning Mechanics & Game Mechanics & Implementation \\
\hline & $\begin{array}{l}\text { Hypothesis } \\
\text { Reflect }\end{array}$ & Narrative/Story & $\begin{array}{l}\text { Use of comic book style and dialogues to } \\
\text { present the story and to allow learner to } \\
\text { hypothesise and reflect on the scenario. }\end{array}$ \\
\cline { 2 - 4 } $\begin{array}{l}\text { To reflect on } \\
\text { knowledge of } \\
\text { cultural stereotypes } \\
\text { and generalisations }\end{array}$ & $\begin{array}{l}\text { Question and } \\
\text { Answer } \\
\text { Identify }\end{array}$ & Selecting & $\begin{array}{l}\text { Embedded questions related to the story, } \\
\text { where learners must select the correct } \\
\text { answer. }\end{array}$ \\
\cline { 2 - 4 } & Feedback & Quiz & $\begin{array}{l}\text { Text, visual and audio feedback has been used } \\
\text { to indicate correct/incorrect answers, and } \\
\text { summary scores. }\end{array}$ \\
Reflection & Scores & $\begin{array}{l}\text { Solutions to the questions are shown, allowing } \\
\text { players to reflect }\end{array}$ \\
\hline
\end{tabular}


The third example is an interactive video (see Figure 5) in Unit 4 of Module 5. This introduces learners to a scenario showing a multi-cultural team hosting a meeting to discuss rapid changes on a project. During the team meeting, managers and employees encounter cultural differences and display certain emotions towards them. Learners attempt to problem solve through the final activity in which they must navigate through the branching narrative and answer questions correctly if they are to achieve a high score and a positive outcome for the scenario's team. The topics covered within this final activity demonstrate the role of emotions, the changes that may be needed in a multi-cultural team, and problem solving in multi-cultural organisations. The simple LM-GM mapping is summarised in Table 5.
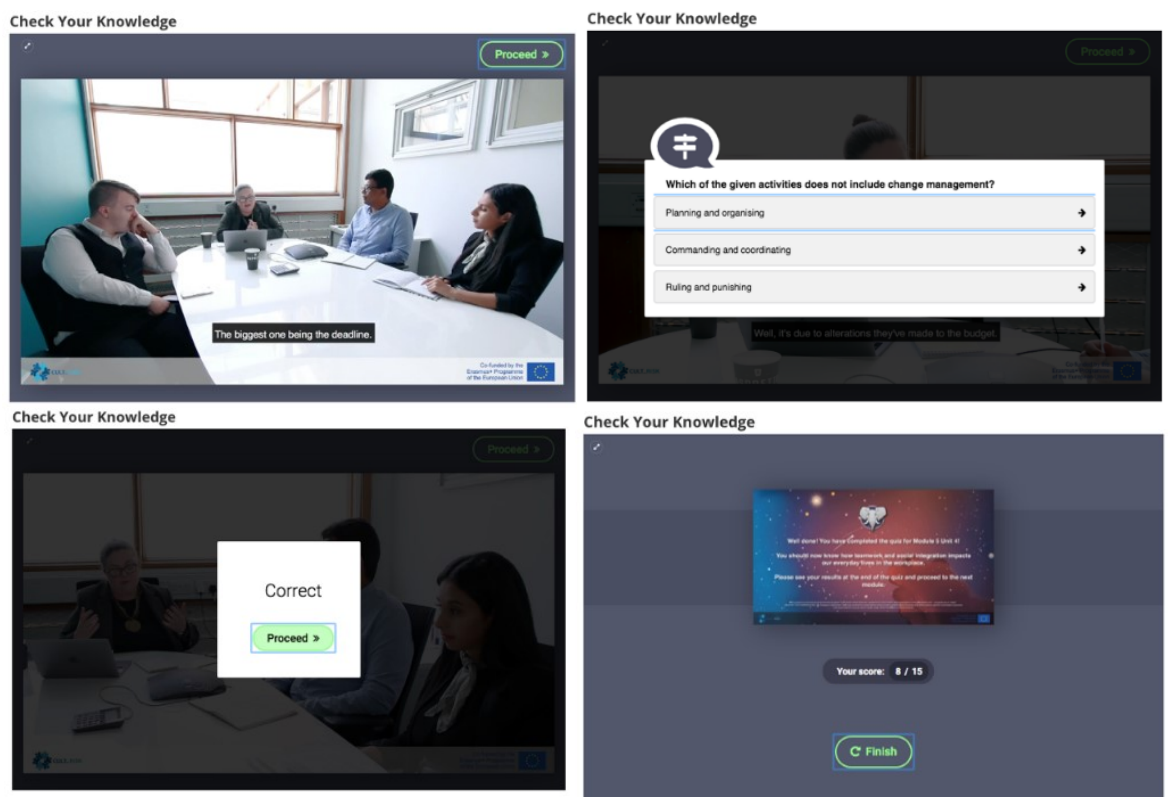

Figure 5: Snapshots of the Video Scenario game authored using H5P

Table 5: Simple LM-GM mapping of a Video-Scenario game

\begin{tabular}{|l|l|l|l|}
\hline Learning Objective & $\begin{array}{l}\text { Learning } \\
\text { Mechanics }\end{array}$ & Game Mechanics & Implementation \\
\hline & $\begin{array}{l}\text { Hypothesis } \\
\text { Reflect }\end{array}$ & $\begin{array}{l}\text { Narrative/Story } \\
\text { Endogenous } \\
\text { fantasy }\end{array}$ & $\begin{array}{l}\text { Use of video scenarios and dialogues to present the } \\
\text { story and to allow the learner to hypothesise and reflect } \\
\text { on the scenario }\end{array}$ \\
\cline { 2 - 4 } $\begin{array}{l}\text { To explore the roles } \\
\text { of emotions and } \\
\text { changes needed in a } \\
\text { multi-cultural team } \\
\text { Answer }\end{array}$ & $\begin{array}{l}\text { Identify } \\
\text { Decision } \\
\text { making }\end{array}$ & $\begin{array}{l}\text { Selecting } \\
\text { Quiz }\end{array}$ & $\begin{array}{l}\text { Embedded questions related to the story, where learners } \\
\text { will have to select the correct answer. }\end{array}$ \\
\cline { 2 - 5 } & Feedback & Scores & $\begin{array}{l}\text { Players navigate through the branching narrative of the } \\
\text { scenario to answer questions correctly }\end{array}$ \\
\hline
\end{tabular}

\section{Findings from the testing of the mini-games}

\subsection{Alpha testing}

Out of the 71 students who engaged with the resources of the online platform and especially the interactive mini-game activities, $96 \%$ found the interactive media to be highly engaging, all students (100\%) found the games to be connected to the learning objectives, where $41 \%$ rated them highly. $93 \%$ of the students stated that the mini-games can be used separately as stand-alone learning resources, which indicates the versatility of the modular approach in populating the online platform with micro-learning activities. 
The mini-games were also ranked by the students for the top 3 that were considered to be both engaging and educational. The frequency is summarised in Table 6.

Table 6: Relative frequency of times mini-games are collectively ranked in top 3

\begin{tabular}{|c|c|c|}
\hline Mini-game types & Frequency (number of times) & Relative Frequency (\%) \\
\hline Drag-and-drop Quiz & 80 & 38 \\
\hline Animated target-and-swipe & 66 & 31 \\
\hline Comic Book & 43 & 20 \\
\hline MCQ Quiz & 24 & 11 \\
\hline Video-based & 0 & 0 \\
\hline
\end{tabular}

The 'drag-and-drop quiz' games include the self-evaluation game on 'what is culture' in Module 1 that was ranked in the top 3 by $48 \%$ of the 71 students, with 24 students rating it as first. $44 \%$ and $21 \%$ of the students ranked Module 7's 'identifying learner's behaviour' and 'learning methods' games in the top 3 respectively. The 'animated target-and-swipe' games include Module 1's self-evaluation game on 'cultural sensitivity' that was selected by $59 \%$ by the students, though this game was only ranked either as a second or third favourite. Module 7 's game on 'recognising learning style' was ranked in the top 3 by $34 \%$ of students. A huge $60 \%$ of students ranked the 'comic-scenario' game in the top 3 that was used as a self-evaluation game at the end of Module 8. Module 7's 'teaching methods for learning styles' game, which is an 'MCQ quiz' game, was ranked in the top 3 by $34 \%$ of students.

\subsection{Beta testing}

The feedback collected from the beta testing phase was used to modify and better adapt the course to the needs of the target groups. The target group included 95 people from partner countries. The questions were the same as those used for the alpha testing phase.

$36 \%$ of the participants stated that interactive resources are highly engaging and $48 \%$ of them rated them as engaging. As for supporting the learning objectives of all the modules, $50 \%$ of the participants stated that they fully agree, and $46 \%$ of them that they agree.

The mini-games were also ranked by the students for the top 3 that they considered to be both engaging and educational. The frequency is summarised in Table 7.

Table 7. Relative frequency of times mini-games are collectively ranked in top 3

\begin{tabular}{|l|c|c|}
\hline Mini-game types & Frequency (number of times) & Relative Frequency (\%) \\
\hline Comic Book & 147 & 52 \\
\hline Animated target-and-swipe & 51 & 18 \\
\hline MCQ Quiz & 42 & 15 \\
\hline Drag-and-drop Quiz & 31 & 11 \\
\hline Video-based & 14 & 5 \\
\hline
\end{tabular}

The 'comic book' type is the most favoured in the top 3 with Module 8's Self Evaluation game - selected by $18 \%$ of the respondents and $59 \%$ of them ranked this 'comic book' as their first choice. Another 'comic book' that has received high interest is Module 1's Cross-cultural awareness - Check your knowledge, where $24 \%$ of the respondents selected this game among which $35 \%$ of them ranked it as first. The 'animated target-and-swipe' games came second with Module 7's self-evaluation game on 'recognising learning styles' that was selected by $84 \%$ of the respondents, and this game was ranked as first (42\%), second (27\%) or third (30\%) favourite. The 'drag-and-drop quiz' games include the self-evaluation game on 'Teaching Methods for Learning Styles' in Module 7 that was ranked in the top 3 by $26 \%$ of the 95 respondents, with 12 respondents rating it as first.

\subsection{Relative frequency in alpha and beta testing phases}

The comparison between the ranked mini-game types in both testing phases is illustrated in Figure 6.

In the alpha test, the 'drag-and-drop' and 'animated target-and-swipe' mini-games are the two most favoured types, which could be due to their simpler, yet intuitive and interactive mechanics that may have achieved better engagement overall. In the beta test however, collectively, the 'drag-and-drop' is the fourth overall favourite. The 'animated target-and-swipe' maintained the second most favoured mini-game type. The 'MCQ quiz' is a 
common format for micro-resources, which was also ranked highly in both testing phases - at fourth and third places respectively. These mini games serve smaller chunks of content per game scene.

The 'comic book' game has the third highest frequency in the alpha test, and one of the six games of this type received the highest number of votes compared to the other games i.e., placed in the top 3 by $60 \%$ of the participants. The preference for this type of game was even higher in the beta test, where the 'comic book' game was rated as first choice by $52 \%$ of the participants. The interest in this mini-game type may be due to the design of the comic characters and also the fictional scenarios that enhance the quizzes. The mix of humour in the content may have allowed a better engagement for the learners. More participants rated this game type highly in the Beta compared to the "Drag and Drop", which could be due to the beta testing mostly engaged practitioners and professionals, who may appreciate the expansion of the content in a narrative form compared to just mere quizzes.

Even though there are 6 'comic book' games (the highest number of games of a single type) on the platform, only two instances of the game (alpha and beta collectively) were ranked in the top 3. The assumption is that overall impact of length and complexity of materials presented as mini-games for micro-learning may be critical in design considerations. The 'Video-based' game was the least attractive for the participants, where none of the two 'video-scenario' games for instance were ranked in the top three in the alpha test. It was only selected 14 times in the beta test, which could also be due to the length and the more serious content of the video scenarios compared to the 'comic book' scenarios.

The mechanics of the 'video-based' games may also be deemed less 'fun' and playful compared to the simpler 'drag-and-drop' and 'target-and-swipe' games. This is an interesting observation as, on reflection, the videoscenario games were the most complicated to design and develop, which may perhaps not be as practical for delivering quick micro-learning materials to learners. This has provided the design team with insights into improvements that can be considered in future.

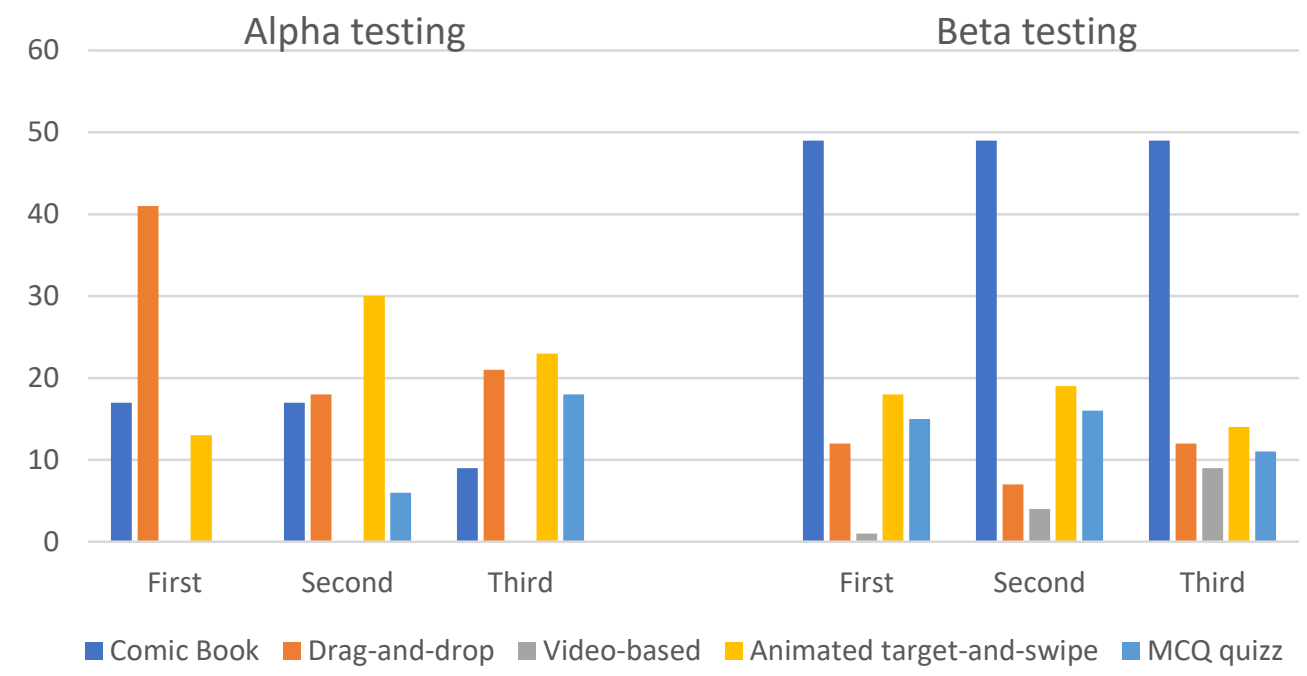

Figure 6: Comparison of the rankings of the mini-games during alpha and beta testing

When compared to the hierarchy of the ranking of the topics associated to the modules (from module 1-8) in Table 1, Module 1 excelled in both the hierarchy and the mini-game preference compared to other topics. Minigame activities in module 7 (the corresponding topic 7 was ranked no. 6 in the hierarchy) have also been consistently ranked in the top 3 in both testing phases collectively. Module 8 , which was ranked seventh in the hierarchy, scored highly in the ranking of the mini-games. Modules 7 and 8 demonstrate that interactive contents, such as mini-games, could have a positive effect on the engagement with topics that were originally deemed less interesting in the earlier phase of the project. 


\section{Conclusions}

To support learners within a work-based environment, especially when related to professional development or development of skills and aptitudes that would increase productivity and improve wellbeing, we need to enable quick and easy access to knowledge and contents that will support this development. Micro-learning has increased in popularity for delivering short bursts of content, which has also proven beneficial for increasing both engagement and learning outcomes. There has been an increase in the use of interactive media for encouraging more active participation in the engagement with content. This includes the use of mini or micro games for complementing and supporting specific learning objectives. Pedagogically informed development of such mini resources is essential, and the balancing of learning and gameplay in the design process requires well thought-out considerations.

This paper describes examples of how such considerations can be included in the design of interactive content associated with the mini-games, where the mechanics of learning (the activities related to the learning process) were mapped against game mechanics (interactions associated to gameplay). Based on the feedback from alpha testing, all learners reported that the games are somewhat connected to the learning objectives. The high rating is slightly low, only $41 \%$ rated them highly. This could be due to the games being used mostly as self-evaluation instruments, where the link to specific learning may not be as explicit.

The use of an ethnicity/cultural agnostic approach in the comic-based games was featured to avoid any potential biases or stereotypes. The comic-based game received the most votes compared to the other games. However, as a game type, only two of the 6 comic book games were selected by the participants in both testing phases collectively. This game type was second in ranking in the alpha test behind the 'drag-and-drop' game in Module 1 , which was voted as first choice, and voted highly in the beta test - being the most ranked in the top 3 . The comic-based game allows for a more narrative-based approach, so learners can put their learning into context.

Narrative and scenarios are also used in the interactive video-based games, which did not appear in the top 3. The interactive videos are longer in nature due to scenarios being acted out by actors and also due to the branching nature of the game. There will be additional studies in the future to gain more comprehensive insights on these types of games within a micro-learning context and to further understand these in terms of time and content complexity.

The mini-game types that are simpler in content representation (e.g. quiz, word cluster) and yet more interactive in nature (e.g. drag-and-drop, target-and-swipe with visual and audio feedback) seem to be a general favourite with the high frequency of votes collectively amongst the participants. The shorter bursts of challenges presented by the games may be found to be more engaging as they do not require the higher level of comprehension demanded by the narrative and scenario-based approaches.

The study could have benefited from further analysis into the actual learning outcomes of the participating learners. Further work will include delivering and evaluating both the platform and the mini-games by engaging managers and employees of multi-cultural organisations. The limitations of the current study will be addressed in the next evaluation to gain more insights into the impact of the complete platform with various resources on the actual learning.

\section{Acknowledgement}

The work is part-funded by the European Commission (Erasmus+ programme - No.2018-1-PL01-KA204-051056 'Cultural Risk in the Organisation in the Globalisation Era - Competences vs. Reality) and the GameChangers initiative.

\section{References}

Alqurashi, E. (2017a). Micro-learning: A Pedagogical Approach for Technology Integration. The Turkish Online Journal of Educational Technology, 2017 942-927.

Alqurashi, E. (2017b). Self-Efficacy and the Interaction Model as Predictors of Student Satisfaction and Perceived Learning in Online Learning Environments (Doctoral dissertation, Duquesne University). Retrieved from https://dsc.duq.edu/etd/194 (24.11.2020).

Anglim, J., Sojo, V., Ashford, L. J., Newman, A., Marty, A. (2019). Predicting employee attitudes to workplace diversity from personality, values, and cognitive ability. Journal of Research in Personality, 83, 1-14. 
Arasaratnam, L.A., Doerfel, M.L. (2005). Intercultural communication competence: Identifying key components from multicultural perspectives. International Journal of Intercultural Relations, 29(2), 137-163.

Arnab S., Lim T., Carvalho M. B., Bellotti F., de Freitas S., Louchart S., Suttie N., Berta R., De Gloria A. (2015). Mapping Learning and Game Mechanics for Serious Games Analysis, British Journal of Educational Technology, 46, 391-411 doi: 10.1111/bjet.12113.

Arnab, S., Clarke, S. (2017). Towards a trans-disciplinary methodology for a game-based intervention development process. British Journal of Educational Technology, 48, 279-312. doi:10.1111/bjet.12377,

Ashkanasy, N. M., Härtel, C. E. J., Daus, C. S. (2002). Diversity and emotion: The new frontiers in organizational behavioral research. Journal of Management, 28, 307-338.

Bussotti, L. (2017). The Italian Way to Intercultural Education: Innovation and Resistance. Foro de Educación, 15(23), 43-68.

CIPD (2018). Annual Report and Accounts 2018-19. Available at https://www.cipd.co.uk/Images/annual-report-2018-2019revised-26-nov-2019_tcm18-67541.pdf (25.11.2020).

Daugeliene R., Greblikaite J., Kurowska-Pysz J., Sroka W., (2016). Cultural Integration and Cross-Cultural Management Challenges in the Central European Countries: Lithuania and Poland. European Integration Studies, 10/2016, $29-43$.

Gaucher, D., Friesen, J., Kay, A.C. (2011). Evidence that gendered wording in job advertisements exists and sustains gender inequality. Journal of Personality and Social Psychology. Vol 101, No 1. 109-128.

Giurgiu, L. (2017). Micro-learning an Evolving Elearning Trend. Buletinul Ştiinţific Al Academiei Trupelor De Uscat, 22(1), 1823. Doi: $10.1515 /$ bsaft-2017-0003.

Hanovs, D. (2016). Can postcolonial theory help explain Latvian politics of integration? Reflections on contemporary Latvia as a postcolonial society, Journal of Baltic Studies, 47(1), 133-153.

Heinz, K. (2014). Multicultural team conflict management. Securitologia, 1/2014, 117-128.

Hussain, S. (2018). Managing Communication Challenges in Multicultural Organizations. Conference: Innovations and Sustainable Growth in Business Management: Opportunities and Challenges, Manuu, India.

Hierdeis, H. (2007). From Meno to Micro-learning: A Historical Survey. In Hug, Th. (Ed.), Didactics of Micro-learning. Concepts, Discourses and Examples, 35-52. Münster, Germany: Waxmann.

Hunicke, R., LeBlanc, M., Zubek, R. (2004). MDA: A Formal Approach to Game Design and Game Research. Proceedings of the Challenges in Game AI Workshop, Nineteenth National Conference on Artificial Intelligence.

Jones, K.P., Peddie, C.I., Gilrane, V.L. et al. (2016). Not so subtle: a meta-analytic investigation of the correlates of subtle and overt discrimination. Journal of Management. Vol 42, No 6, 1588-1613.

Kapp, K. M., Defelice, R. M. (2019). Micro-learning: Short and Sweet. Alexandria: ATD Press.

Lane, S.R., Flowers, T.D. (2015). Salary inequity in social work: a review of the knowledge and call to action. Affilia. Vol. 30, No 3, 363-379.

Masulis, R.W., Wang, C., Xie, F. (2012). Globalizing the boardroom-the effects of foreign directors on corporate governance and firm performance. Journal of Accounting and Economics, 53, 527-554.

Mayer, R.E, Moreno, R,. Boire, M., Vagge, S. (1999). Maximizing constructivist learning from multimedia communications by minimizing cognitive load. J Educ Psychol.

McLaughlin, M.E., Bell, M.P., Stringer, D.Y. (2004). Stigma and acceptance of persons with disabilities: understudied aspects of workforce diversity. Group and Organization Management. Vol 29, No 3, 302-333.

Ochieng, E.G., Price, A.D.F. (2010). Managing cross-cultural communication in multicultural construction project teams: The case of Kenya and UK. International Journal of Project Management, 28(5), 449-460.

Quillian, L., Pager, D., Hexel, O. et al. (2017). Meta-analysis of field experiments shows no change in racial discrimination in hiring over time. Proceedings of the National Academy of Sciences. Vol 114, No 41, 10870-10875.

Rosmalen, P., Boyle, E., Baaren, J., Kärki, A. and Aguado, Á. (2014). A case study on the design and development of minigames for research methods and statistics. EAI Endorsed Transactions on Game-Based Learning. 1. e5. 10.4108/sg.1.3.e5.

Rožukalne, A., Kruks, S., Skulte, I., Lūse, A., Stakle, A. (2017). Migrācijas atspoguḷojums un rāmējums Latvijas medijos (20152016)

https://www.km.gov.lv/uploads/ckeditor/files/Sabiedribas_integracija/Petijumi/Migracijas\%20atspogulojums\%20un \%20ramejums\%20LV\%20medijos(2017).pdf (24.11.2020).

Scarborough, W.J., Lambouths, D.L., Holbrook, A.L. (2019). Support of workplace diversity policies: The role of race, gender, and beliefs about inequality. Social Science Research, 79, 194-210.

Segal, U.A. (2019). Globalization, migration, and ethnicity. Public Health, 172, 135-142.

Shail, M. S. (2019). Using Micro-learning on Mobile Applications to Increase Knowledge Retention and Work Performance: A Review of Literature. Cureus 11(8): e5307.

Singh, D. (2014). Managing cross-cultural diversity: issues and challenges in global organizations. IOSR Journal of Mechanical and Civil Engineering. International Conference on Recent Trends in Engineering and Management.

Triana, M.D.C., Jaysinghe, M. \& Pieper, J.R. (2015). Perceived workplace racial discrimination and its correlates: a metaanalysis. Journal of Organizational Behavior. Vol 36, No 4, 491-513.

Walaszczyk, L. (2020). Social Innovation Based-Model for the Analysis of Enterprise Operations. Institute for Sustainable Technologies, Radom.

Wang, Z., Luo, Y., \& Qu, Y. (2017). Application of Micro-lecture For Engineering Mechanics Experimental Teaching. International Journal of Innovation and Research in Educational Sciences, (4)2, 130-132. 


\section{Appendix 1:}

Polish organisation

\begin{tabular}{|l|l|l|l|l|l|l|l|l|l|}
\hline Preference Matrix for the Modules & M1 & M2 & M3 & M4 & M5 & M6 & M7 & M8 & Eigenvector \\
\hline Normalised Matrix & M1 & M2 & M3 & M4 & M5 & M6 & M7 & M8 & mean K \\
\hline M1: Cross Cultural Awareness & 0.35 & 0.55 & 0.224 & 0.251 & 0.281 & 0.217 & 0.252 & 0.252 & 0.298 \\
\hline M2: Understanding Different Cultures & 0.11 & 0.18 & 0.280 & 0.251 & 0.375 & 0.217 & 0.252 & 0.252 & 0.241 \\
\hline M3: Stereotypes & 0.08 & 0.03 & 0.056 & 0.251 & 0.031 & 0.043 & 0.101 & 0.017 & 0.078 \\
\hline M4: Communication & 0.11 & 0.06 & 0.019 & 0.084 & 0.094 & 0.217 & 0.202 & 0.101 & 0.112 \\
\hline M5: Teamwork & 0.11 & 0.04 & 0.168 & 0.084 & 0.094 & 0.087 & 0.101 & 0.151 & 0.106 \\
\hline M6: Leadership and Hierarchy & 0.07 & 0.03 & 0.056 & 0.017 & 0.047 & 0.043 & 0.025 & 0.025 & 0.040 \\
\hline M7: Learning Styles & 0.07 & 0.03 & 0.028 & 0.021 & 0.047 & 0.087 & 0.050 & 0.151 & 0.061 \\
\hline M8: Qualities in the Working Place & 0.07 & 0.03 & 0.168 & 0.042 & 0.031 & 0.087 & 0.017 & 0.050 & 0,063 \\
\hline
\end{tabular}

Italian organisation

\begin{tabular}{|l|l|l|l|l|l|l|l|l|l|}
\hline Preference Matrix for the Modules & $\mathrm{M} 1$ & $\mathrm{M} 2$ & $\mathrm{M} 3$ & $\mathrm{M} 4$ & $\mathrm{M} 5$ & $\mathrm{M} 6$ & $\mathrm{M} 7$ & $\mathrm{M} 8$ & Eigenvector \\
\hline Normalised Matrix & $\mathrm{M} 1$ & $\mathrm{M} 2$ & $\mathrm{M} 3$ & $\mathrm{M} 4$ & $\mathrm{M} 5$ & $\mathrm{M} 6$ & $\mathrm{M} 7$ & $\mathrm{M} 8$ & mean K \\
\hline M1: Cross Cultural Awareness & 0.280 & 0.253 & 0.224 & 0.251 & 0.316 & 0.217 & 0.282 & 0.212 & 0.255 \\
\hline $\begin{array}{l}\text { M2: Understanding Different } \\
\quad \text { Cultures }\end{array}$ & 0.280 & 0.253 & 0.224 & 0.251 & 0.316 & 0.217 & 0.113 & 0.159 & 0.227 \\
\hline M3: Stereotypes & 0.070 & 0.063 & 0.056 & 0.251 & 0.035 & 0.043 & 0.113 & 0.018 & 0.081 \\
\hline M4: Communication & 0.093 & 0.084 & 0.019 & 0.084 & 0.105 & 0.217 & 0.226 & 0.106 & 0.117 \\
\hline M5: Teamwork & 0.093 & 0.084 & 0.280 & 0.084 & 0.105 & 0.087 & 0.169 & 0.159 & 0.133 \\
\hline M6: Leadership and Hierarchy & 0.056 & 0.051 & 0.056 & 0.017 & 0.053 & 0.043 & 0.028 & 0.027 & 0.041 \\
\hline M7: Learning Styles & 0.056 & 0.127 & 0.028 & 0.021 & 0.035 & 0.087 & 0.056 & 0.265 & 0.084 \\
\hline M8: Qualities in the Working Place & 0.070 & 0.084 & 0.112 & 0.042 & 0.035 & 0.087 & 0.011 & 0.053 & 0,062 \\
\hline
\end{tabular}

Cypriot organisation

\begin{tabular}{|c|c|c|c|c|c|c|c|c|c|}
\hline Preference Matrix for the Modules & M1 & $\mathrm{M} 2$ & M3 & M4 & M5 & M6 & M7 & M8 & Eigenvector \\
\hline Normalised Matrix & M1 & M2 & M3 & M4 & M5 & M6 & M7 & M8 & mean $\mathrm{K}$ \\
\hline M1: Cross Cultural Awareness & 0.24 & 0.22 & 0.145 & 0.274 & 0.31 & 0.217 & 0.190 & 0.189 & 0.225 \\
\hline M2: Understanding Different Cultures & 0.24 & 0.22 & 0.145 & 0.183 & 0.31 & 0.261 & 0.127 & 0.126 & 0.203 \\
\hline M3: Stereotypes & 0.12 & 0.11 & 0.072 & 0.274 & 0.03 & 0.043 & 0.127 & 0.021 & 0.101 \\
\hline M4: Communication & 0.08 & 0.11 & 0.024 & 0.091 & 0.10 & 0.217 & 0.254 & 0.126 & 0.127 \\
\hline M5: Teamwork & 0.08 & 0.07 & 0.361 & 0.091 & 0.10 & 0.087 & 0.190 & 0.189 & 0.148 \\
\hline M6: Leadership and Hierarchy & 0.05 & 0.03 & 0.072 & 0.018 & 0.05 & 0.043 & 0.032 & 0.032 & 0.042 \\
\hline M7: Learning Styles & 0.08 & 0.11 & 0.036 & 0.023 & 0.03 & 0.043 & 0.063 & 0.253 & 0.081 \\
\hline M8: Qualities in the Working Place & 0.08 & 0.11 & 0.145 & 0.046 & 0.03 & 0.087 & 0.016 & 0.063 & 0,073 \\
\hline
\end{tabular}


Latvian organisation

\begin{tabular}{|c|c|c|c|c|c|c|c|c|c|}
\hline Preference Matrix for the Modules & M1 & $\mathrm{M} 2$ & M3 & M4 & M5 & M6 & M7 & M8 & Eigenvector \\
\hline Normalised Matrix & M1 & M2 & M3 & M4 & M5 & M6 & M7 & M8 & mean $\mathrm{K}$ \\
\hline M1: Cross Cultural Awareness & 0.20 & 0.20 & 0.156 & 0.272 & 0.32 & 0.130 & 0.085 & 0.178 & 0.195 \\
\hline M2: Understanding Different Cultures & 0.20 & 0.20 & 0.156 & 0.181 & 0.32 & 0.261 & 0.085 & 0.178 & 0.200 \\
\hline M3: Stereotypes & 0.10 & 0.10 & 0.078 & 0.272 & 0.03 & 0.043 & 0.169 & 0.020 & 0.103 \\
\hline M4: Communication & 0.06 & 0.10 & 0.026 & 0.091 & 0.10 & 0.217 & 0.254 & 0.119 & 0.123 \\
\hline M5: Teamwork & 0.06 & 0.06 & 0.390 & 0.091 & 0.10 & 0.130 & 0.254 & 0.238 & 0.168 \\
\hline M6: Leadership and Hierarchy & 0.06 & 0.03 & 0.078 & 0.018 & 0.03 & 0.043 & 0.042 & 0.030 & 0.044 \\
\hline M7: Learning Styles & 0.20 & 0.20 & 0.039 & 0.030 & 0.03 & 0.043 & 0.085 & 0.178 & 0.103 \\
\hline M8: Qualities in the Working Place & 0.06 & 0.06 & 0.078 & 0.045 & 0.02 & 0.130 & 0.028 & 0.059 & 0.063 \\
\hline
\end{tabular}

British organisation

\begin{tabular}{|l|l|l|l|l|l|l|l|l|l|}
\hline Preference Matrix for the Modules & M1 & M2 & M3 & M4 & M5 & M6 & M7 & M8 & Eigenvector \\
\hline Normalised Matrix & M1 & M2 & M3 & M4 & M5 & M6 & M7 & M8 & mean $\mathrm{K}$ \\
\hline M1: Cross Cultural Awareness & 0.25 & 0.20 & 0.337 & 0.197 & 0.381 & 0.200 & 0.217 & 0.202 & 0.249 \\
\hline M2: Understanding Different Cultures & 0.25 & 0.20 & 0.135 & 0.197 & 0.286 & 0.200 & 0.072 & 0.202 & 0.194 \\
\hline M3: Stereotypes & 0.05 & 0.10 & 0.067 & 0.295 & 0.032 & 0.050 & 0.145 & 0.022 & 0.096 \\
\hline M4: Communication & 0.12 & 0.10 & 0.022 & 0.098 & 0.095 & 0.150 & 0.217 & 0.135 & 0.119 \\
\hline M5: Teamwork & 0.06 & 0.06 & 0.270 & 0.098 & 0.095 & 0.150 & 0.217 & 0.135 & 0.137 \\
\hline M6: Leadership and Hierarchy & 0.06 & 0.05 & 0.067 & 0.033 & 0.032 & 0.050 & 0.036 & 0.034 & 0.046 \\
\hline M7: Learning Styles & 0.08 & 0.20 & 0.034 & 0.033 & 0.032 & 0.050 & 0.072 & 0.202 & 0.089 \\
\hline M8: Qualities in the Working Place & 0.08 & 0.06 & 0.067 & 0.049 & 0.048 & 0.150 & 0.024 & 0.067 & 0.070 \\
\hline
\end{tabular}

Source: Author. 